
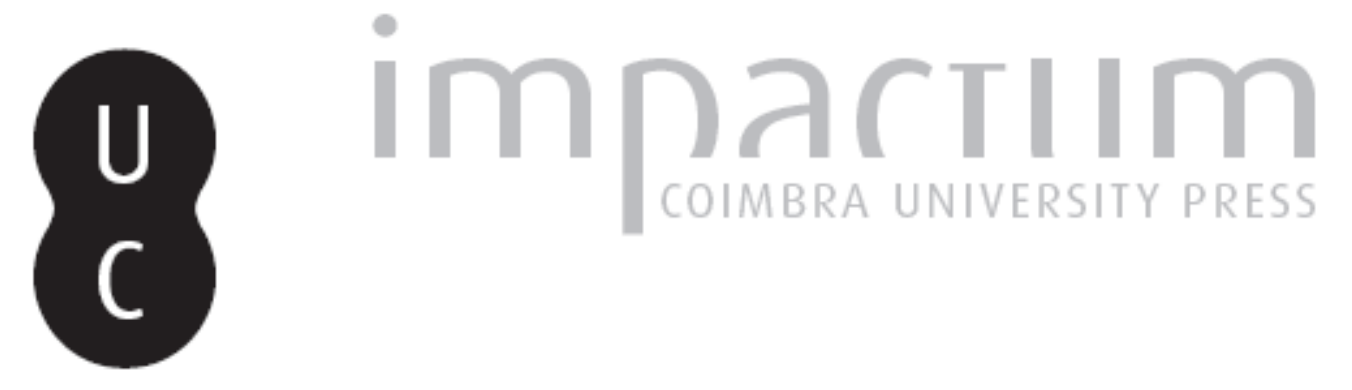

Responsabilidade médica: a propósito de alguns casos do concelho de Coimbra

Autor(es): $\quad$ Castanheira, Gonçalo

Publicado por: Imprensa da Universidade de Coimbra

URL persistente:

URI:http://hdl.handle.net/10316.2/43560

DOI: $\quad$ DOI:https://doi.org/10.14195/1647-8630_27_4

Accessed : $\quad$ 26-Apr-2023 07:35:26

A navegação consulta e descarregamento dos títulos inseridos nas Bibliotecas Digitais UC Digitalis, UC Pombalina e UC Impactum, pressupõem a aceitação plena e sem reservas dos Termos e Condições de Uso destas Bibliotecas Digitais, disponíveis em https://digitalis.uc.pt/pt-pt/termos.

Conforme exposto nos referidos Termos e Condições de Uso, o descarregamento de títulos de acesso restrito requer uma licença válida de autorização devendo o utilizador aceder ao(s) documento(s) a partir de um endereço de IP da instituição detentora da supramencionada licença.

Ao utilizador é apenas permitido o descarregamento para uso pessoal, pelo que o emprego do(s) título(s) descarregado(s) para outro fim, designadamente comercial, carece de autorização do respetivo autor ou editor da obra.

Na medida em que todas as obras da UC Digitalis se encontram protegidas pelo Código do Direito de Autor e Direitos Conexos e demais legislação aplicável, toda a cópia, parcial ou total, deste documento, nos casos em que é legalmente admitida, deverá conter ou fazer-se acompanhar por este aviso. 
ISSN: 1645-0760

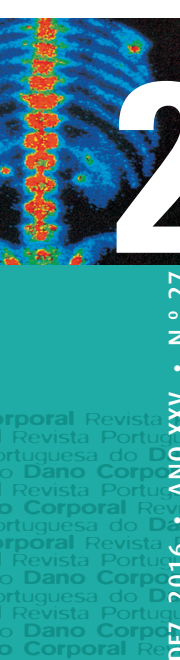

REVISTA PORTU/GUESA
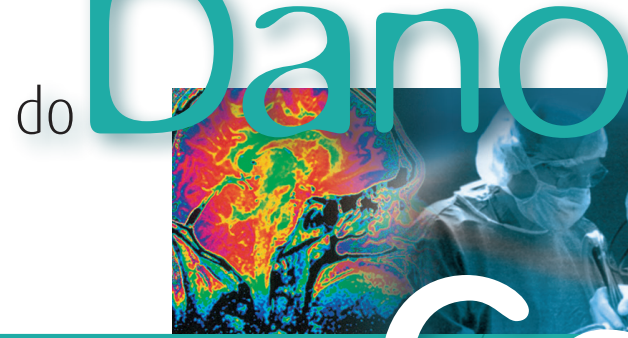

N

z.

希ort

Do

: inta Cortuguesa do Dano Corporal Revista Portuguesa do Dano Corporal Revista Portuguesa

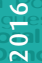

ầं।

Corporal Revista Portuguesa do Dano Corporal Revista Portuquesa do Dano Corporal

I Revista Portuguesa do Dano Cortuguesa do Dano Corporal Revista Portugues
Revista Pdrtuguesa do Dano Corporal

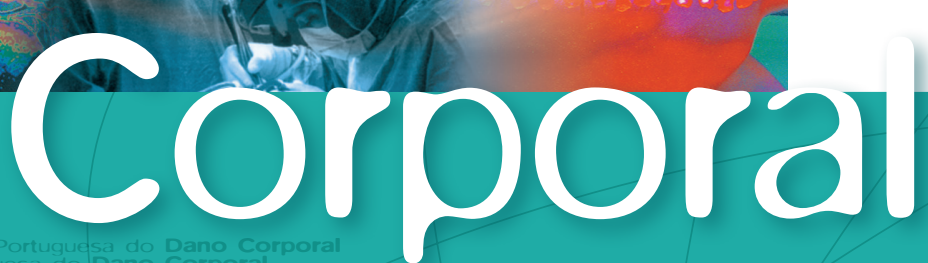

APADAC

ASSOCIAÇÃO PORTUGUESA

DE AVALIAÇÃO

DO DANO CORPORAL 


\title{
Responsabilidade médica. A propósito de alguns casos do concelho de Coimbra
}

\author{
Gonçalo Castanheira ${ }^{1}$
}

O médico é por vezes obrigado a tomar decisões num espaço de instantes, fazer um diagnóstico, escolher uma terapêutica.

Tal decisão e escolha poderão vir a tornar-se, a posteriori, objeto de numerosos inquéritos, de discussões de peritos, de audiências consecutivas e de longas reflexões judiciais.

Resumo: Responsabilidade médica - a propósito de alguns casos do concelho de Coimbra. A responsabilidade profissional em saúde reporta-se aos deveres e obrigações que os seus profissionais assumem no exercício da sua profissão.

0 médico é técnica e deontologicamente independente e responsável pelos seus atos, devendo observar o maior respeito pelo direito à proteção da saúde das pessoas e da comunidade, sem ultrapassar os limites das suas qualificações e competências.

Até há poucas décadas atrás pouco se discutia ou se escrevia sobre a responsabilidade profissional em saúde. No imaginário coletivo o médico era uma figura mítica, um benfeitor que intervinha sempre para o bem do doente. Atualmente a Medicina concentra-se estritamente nos avanços da tecnologia e da ciência, exagerando os seus benefícios e ignorando ou minorando os seus perigos, começando os prestadores de cuidados de saúde a serem avassalados por reclamações, processos disciplinares e judiciais.

0 Conselho Médico Legal, um dos quatro órgãos do Instituto Nacional de Medicina Legal e Ciências Forenses, exerce funções de consultadoria técnico-científica e ética, através da emissão de pareceres sobre questões concretamente colocadas. No âmbito da atuação deste Conselho foram revistos os processos a ele endereçados referentes a unidades de saúde do concelho de Coimbra - Portugal, considerado uma referência nacional na área da saúde.

Palavras-chave: Responsabilidade médica; responsabilidade profissional em saúde; leges artis; Conselho Médico-Legal; Coimbra; Portugal.

1 Médico especialista em Medicina Legal; Instituto Nacional de Medicina Legal e Ciências Forenses, IP. 
Summary: Medical responsibility in Coimbra - Portugal

Professional responsibility in health refers to the duties and obligations that its professionals assume in the exercise of their profession.

The doctor is technically and deontologically independent and responsible for his or her actions, and should observe the highest respect for the right to the protection of the health of people and the community, without exceeding the limits of their qualifications and competences.

Until a few decades ago little was discussed or written about professional responsibility in health. In the collective imagination the physician was a mythical figure, a benefactor who always intervened for the good of the patient. Today Medicine focuses strictly on advances in technology and science, exaggerating its benefits and ignoring or mitigating its dangers, beginning healthcare providers to be overwhelmed by complaints, disciplinary and judicial processes. The Legal Medical Council, one of the four organs of the National Institute of Legal Medicine and Forensic Sciences of Portugal (INMLCF), performs technical-scientific and ethical consultancy functions, through the issuance of opinions on specific questions. In the scope of this Council's action, the processes addressed to it referring to health units of Coimbra - Portugal, considered a national reference in health area, were reviewed.

Key-words: Medical liability; professional health responsibility; Conselho Médico-Legal; Coimbra; Portugal.

\section{INTRODUÇÃO}

A responsabilidade médica consiste na obrigação de reparar e satisfazer as consequências prejudiciais dos atos, omissões e erros voluntários, e também involuntários, cometidos no exercício profissional da Medicina, dentro de determinados limites.

Os deveres do médico são vastos, visto que este desempenha uma função transcendente e que nenhuma outra profissão tem nas suas mãos a vida dos seres humanos.

Ao médico não é exigível que seja infalível, mas que proceda em conformidade com os conhecimentos da Medicina e com o indispensável zelo e respeito pela pessoa do doente.

O médico deve atuar de acordo com o cuidado, a perícia e os conhecimentos compatíveis com os padrões por que se regem os médicos sensatos, razoáveis e competentes. Mas se porventura ele tem, ou se arroga ter, conhecimentos superiores à média, em qualquer tipo de tratamento, intervenção cirúrgica e riscos inerentes, poderá ser obrigado a redobrados cuidados. Por outro lado, deve manter-se razoavelmente atualizado, através de um esforço permanente, não podendo obstinadamente e de modo estulto prosseguir 
com a utilização de métodos antiquados, se estiver demonstrado que tais métodos não são aceites pela generalidade da opinião médica informada.

Nas últimas décadas temos assistido a importantes descobertas e avanços na Medicina, que provocaram alterações demográficas, na Economia, na Ética e no Direito, e que a sociedade nem sempre se mostrou preparada para assimilar.

Assistimos, também, a um aumento da complexidade da actividade médica da qual emergiu um novo tipo de médico. Faz parte das memórias do passado a figura do "médico de cabeceira" que detinha todo o conhecimento da arte de curar na sua cabeça e na sua maleta. A "relação hipocrática pessoal”, baseada na relação dual médico-doente, foi substituída por um trabalho coletivo de prestação de cuidados de saúde, que opera em estruturas hospitalares cada vez mais complexas, tanto na tecnologia como na organização.

Por outro lado, a sociedade de comunicação em que hoje vivemos publicita de modo célere os magníficos avanços e êxitos da Medicina, criando naturais expectativas nos doentes e nas suas famílias, reduzindo, concomitantemente, as margens de aceitação do insucesso. Com uma melhor formação cultural, os doentes estão a tomar consciência dos seus direitos e a deixarem de se resignar com o erro médico.

Deste modo, nos últimos anos, em Portugal, as demandas contra os profissionais de saúde tornaram-se uma realidade no exercício da Medicina, tendo aumentado as reclamações, os processos disciplinares e judiciais, sendo de esperar que um volume de processos muito superior ao atual comece a dar entrada nos tribunais.

A decisão mais segura sob o ponto de vista da responsabilidade nem sempre é a melhor para o doente. Se o médico opta por proceder à realização de exames preliminares em vez de proceder de imediato a certa intervenção, dir-se-á que, na trágica corrida contra o tempo, a morte saiu vitoriosa sobre a perícia e competência médicas. Mas se, ao contrário, o médico assume o risco de proceder à intervenção que lhe parece mais adequada, sem ter realizado os exames que em condições normais se impunham, na esperança de ganhar tal corrida, e o ferido vem a morrer na mesa de operações, pode bem acontecer que venha a ser censurado por ter privado o doente de uma esperança de vida que o exame preliminar, porventura, poderia ter preservado.

As diferenças de opinião são compatíveis com o exercício de um razoável cuidado e competência, ou mesmo com um elevadíssimo grau de cuidado, não sendo o médico considerado culpado por erro de diagnóstico ou de apreciação enquanto não se conseguir provar que este atuou de forma contrária às leges artis reconhecidas pela profissão. 
O juiz de hoje, como o juiz do futuro, é seguramente um decisor a quem escasseiam o tempo e as capacidades para tudo saber, tudo estudar e tudo investigar, devendo por isso socorrer-se - como a mais natural e a mais inteligente das soluções - do auxílio daqueles a quem, por força da sua especial preparação técnica e prática, é reconhecida uma competência profissional acrescida e à qual se convencionou chamar perícia.

Assim, o Conselho Médico-Legal do Instituto Nacional de Medicina Legal e Ciências Forenses, composto por médicos de lugares cimeiros de instituições e organismos de referência e dirigentes máximos de instituições com funções coadjuvantes ou auxiliares de justiça, superiormente qualificados sob o ponto de vista académico e de probidade indiscutível sob o ponto de vista humano, reúne as condições de competência, imparcialidade, isenção e rigor que a tarefa de despistagem e prova da responsabilidade de um médico necessariamente pressupõe e exige.

\section{OBJECTIVOS}

O presente artigo tem como objectivo a apresentação de alguns casos de responsabilidade médica interessando unidades de saúde do concelho de Coimbra, remetidos ao Conselho Médico Legal do Instituto Nacional de Medicina Legal e Ciências Forenses, e análise de existência, ou não, de concordância entre as conclusões dos pareceres emitidos por este Conselho e as respetivas decisões judiciais.

\section{CASOS}

A preocupação do médico tem de ser proteger a mãe e só secundariamente o feto

Os autos tiveram origem numa denúncia efectuada no Ministério Público, pela própria doente, dando conta de situações que poderiam revelar falta de zelo e diligência nos seguintes cuidados de saúde que lhe foram prestados:

- Primigesta de 39 anos, acompanhada em consulta pré-natal, sem anomalias relevantes. 
- Às 26 semanas de idade gestacional é detetado "quisto com $3 \mathrm{~cm}$ de diâmetro no pequeno lábio esquerdo", e às 29 semanas "mantém quisto da glândula de Bartholin no grande lábio esquerdo".

- Às 30 semanas é observada no serviço de urgência de uma maternidade da cidade de Coimbra, tendo sido efectuada a hipótese diagnóstica de "quisto da glândula de Bartholin infectado". Foi realizada drenagem, que só drenou sangue, pelo que foi enviada para o bloco operatório com o diagnóstico de "abcesso da glândula de Bartholin à esquerda".

- O relato da intervenção referiu "formação tumoral vulvar aparentemente de conteúdo líquido na metade posterior do grande lábio esquerdo, com $5 \mathrm{~cm}$ de diâmetro, sugerindo tratar-se de abcesso da glândula de Bartholin". Após ligeiro toque com a ponta do bisturi na mucosa que recobria a lesão resultou abundante hemorragia que motivou estado de choque hemorrágico, com necessidade de administração de várias unidades de sangue durante a intervenção e nos dias que se seguiram.

- No dia seguinte a hemorragia estava controlada, mas constatou-se a morte fetal, tendo sido efectuada "extração fetal por cesariana”.

- O relatório do exame necrópsico concluiu por "sinais de morte fetal in útero por hipoxia de provável causa placentar" e o estudo anátomo-patológico da placenta revelou "lesões de isquémia útero-placentar aguda".

Foi pedida consulta técnico-científica ao Conselho Médico-Legal que, ao quesito se seria exigível a "retirada prévia do feto do ventre materno", respondeu que "nas circunstâncias descritas a prioridade absoluta era o controlo cirúrgico da hemorragia e não havia indicação para extração fetal prévia”.

Durante a fase de inquérito foram inquiridos outros médicos, que confirmaram que "numa situação tão grave, a preocupação do médico tem de ser proteger a mãe e só secundariamente o feto" e que "só quando estivessem controlados os sinais vitais da mãe é que se poderia pensar no feto".

Não tendo sido demonstrada qualquer inobservância das regras de comportamento exigíveis à actividade médica (leges artis), só restou, pois, concluir pela insuficiência de indícios quanto à verificação de qualquer infração criminal, razão pela qual foi determinado o arquivamento dos respetivos autos.

A obtenção de um diagnóstico evitaria a morte da menina

O Ministério Público acusou dois médicos - um pediatra e um cirurgião-pediatra - de um hospital da cidade de Coimbra, pelos seguintes factos: 
- Menina de 10 anos de idade que deu entrada num hospital da cidade de Coimbra, transferida do centro de saúde da sua área de residência, com o diagnóstico de "1. Gastroenterite aguda? 2. Apendicite aguda? Diagnóstico diferencial (...)".

- Referia queixas de vómitos e diarreia, anorexia e quadro doloroso abdominal, mais acentuado à direita. Foi observada pelo referido cirurgião-pediatra que, ao exame objectivo, referiu temperatura febril e sinal de Blumberg inconclusivo.

- O mesmo médico entendeu não proceder a qualquer exame complementar de diagnóstico, designadamente uma ecografia abdominal, a fim de estabelecer o diagnóstico diferencial entre gastroenterite e apendicite aguda, baseando-se apenas nos exames efetuados no centro de saúde do qual era proveniente.

- Ao invés, e por lhe parecer não se tratar de uma situação cirúrgica, não estabelecendo o diagnóstico diferencial, decidiu enviar a doente a uma consulta com o outro médico pediatra atrás referido, que a observou ainda no mesmo dia. Nesta nova observação, após palpação abdominal, o médico pediatra afirmou não se tratar de um caso de apendicite aguda, pelo que a medicou para as dores e lhe deu alta clínica.

- No dia seguinte, já no domicílio, por não apresentar sinais de melhoria, recorreu, a título particular, a outro médico pediatra, que confirmou os sinais característicos de apendicite aguda.

- Foi de imediato transportada para o serviço de urgência do hospital da cidade de Coimbra, de onde tinha tido alta no dia anterior.

- Durante a viagem a doente viria a falecer.

Foi submetida a autópsia médico-legal, que confirmou que a morte foi devida a apendicite aguda.

Foi solicitada consulta técnico-científica ao Conselho Médico-Legal, acerca da concreta atuação clínica dos dois médicos arguidos, que concluiu que "se justificaria uma maior atenção e rigor da exploração, com exames complementares e não, apenas, clínica”, e que "o internamento permitiria um mais apertado e melhor controlo e avaliação clínica do caso, permitindo o diagnóstico da gravidade da evolução e a intervenção cirúrgica atempada, que, eventualmente, poderia ter evitado a morte”.

A não subscrição de qualquer diagnóstico, por parte dos dois médicos, relativamente à concreta patologia da doente, conforme lhes era exigido face aos seus conhecimentos, viola as leges artis e é concausa da morte da doente.

Foi deduzida acusação pelo Ministério Público na qual se concluiu: ao atuarem deste modo, os arguidos violaram de forma grave o dever de 
cuidado a que se encontravam obrigados e de que eram capazes, pelo que incorreram na prática de um crime de homicídio por negligência.

Posteriormente foi requerida instrução pelos dois arguidos, e, após indiciados de forma suficiente os factos apontados na acusação pública, foram pronunciados, tendo os autos sido remetidos para julgamento.

\section{0 toque vaginal permitiria o internamento evitando a morte do feto?}

O Ministério Público deduziu acusação contra um médico obstetra de uma maternidade da cidade de Coimbra, pelos seguintes factos:

- Grávida de 29 semanas de gestação, com 36 anos de idade, que se dirigiu ao serviço de urgência de uma maternidade da cidade de Coimbra com queixas de "dores abdominais, disúria e corrimento vaginal ensanguentado".

- Foi assistida por um médico obstetra, tendo realizado diversos exames serológicos. Foram ainda ouvidos os batimentos cardíacos do feto, não tendo sido realizado qualquer outro exame obstétrico. Teve alta para o domicílio, medicada, com o diagnóstico de "infeção urinária".

- Cerca de 3 horas após a alta, a doente verificou "agravamento das dores e perdas sanguíneas”, apercebendo-se que "o bebé começava a deslizar pelo canal vaginal, em direção ao exterior”, pelo que recorreu ao hospital distrital mais próximo da sua residência.

- Face à eminência do parto e à falta de equipamentos deste hospital, a doente foi imediatamente transferida para a maternidade da cidade de Coimbra de onde havia tido alta horas antes.

- À entrada desta maternidade, a doente já se encontrava em trabalho de parto, em pleno período expulsivo do feto com apresentação pélvica. Este viria a sofrer hipoxia aguda, por privação de oxigenação fetal provocada pelas contrações uterinas, que lhe causou a morte.

- O feto não tinha qualquer malformação, apresentava parâmetros de crescimento e maturação concordantes com a idade gestacional, pelo que seria viável.

Foi solicitada consulta técnico-científica ao Conselho Médico-Legal, que concluiu que "a sintomatologia clínica imporia um exame por toque vaginal com o objectivo de determinar se as queixas de dores abdominais e de perdas sanguíneas vaginais configurariam, ou não, uma situação de trabalho de parto pré-termo em início. Se o toque vaginal tivesse sido efetuado, a grávida poderia ter sido internada para observação e tratamento". 
Foi deduzida acusação pelo Ministério Público na qual se concluiu: ao omitir esse exame e ao não manter a grávida sob observação, remetendo-a para o domicílio, o médico arguido violou as leges artis profissionais, sendo responsável pela ocorrência do parto sem assistência médica.

Ao não atuar de acordo com as normas e procedimentos profissionais que conhecia e que, como obstetra, era capaz de cumprir, o arguido deu causa à morte do bebé, constituindo-se, assim, como autor material de um crime de homicídio por negligência.

Posteriormente, o referido médico arguido, não se conformando com o referido despacho de acusação requereu abertura de instrução. No entanto, a prova trazida aos autos em sede de instrução não infirmou a prova recolhida no inquérito, aliás, ainda a corroborou com os esclarecimentos do relator do Conselho Médico-Legal do Instituto Nacional de Medicina Legal e Ciência Forenses.

Em consequência, o Tribunal de Instrução Criminal não pôde deixar de formular um juízo de probabilidade de aplicação ao arguido de uma reacção criminal pelo crime de homicídio negligente de que era acusado, tendo proferido despacho de pronúncia.

Os pretensos pais deduziram ainda um pedido de indemnização civil contra o médico obstetra, a título de danos não patrimoniais, no valor de $90.000 €$.

Realizada a audiência de discussão e julgamento em tribunal de $1^{\mathrm{a}}$ instância, foi solicitado parecer ao Colégio da Especialidade de Obstetrícia, que concluiu que "a atitude médica pode ser considerada boa prática médica". Foram ainda ouvidos outros médicos obstetras, como testemunhas, que emitiram opiniões no mesmo sentido: "o diagnóstico feito pelo arguido foi o correto e, no lugar dele, não teria feito o toque vaginal", "é desadequado e desaconselhável fazer o toque vaginal perante um quadro de infeção urinária, na ausência de contrações" e "perante o diagnóstico de infeção urinária, o tratamento e o procedimento foram os corretos e não havia razão nem para fazer toque vaginal nem para o internamento".

Conjugando todos estes elementos, deu-se como não provado que o arguido tenha violado, com a sua conduta, as regras da boa prática médica, concluindo-se que o arguido não praticou o crime de que era acusado, nem outro pelo qual devesse ser condenado. Relativamente ao pedido de indemnização civil, concluiu-se que o arguido não praticou qualquer facto ilícito, pelo que o pedido foi considerado improcedente.

Posto isto, o Ministério Público, inconformado com a sentença, interpôs recurso para tribunal de $2^{\mathrm{a}}$ instância. 
Corpo estranho retido no abdómen de uma doente após cirurgia

Os autos de inquérito iniciaram-se nos Serviços do Ministério Público com uma denúncia apresentada por um indivíduo do género feminino de 59 anos de idade, relacionada com as circunstâncias que rodearam uma cirurgia à qual foi submetida num hospital da cidade de Coimbra.

- Após uma cirurgia digestiva programada - hepatectomia major - foi esquecida dentro do abdómen da doente uma pinça hemostática de Crawford com $18 \mathrm{~cm}$ de comprimento.

- Saliente-se a realização de um estudo ecográfico solicitado e observado pelo mesmo cirurgião, cerca de seis meses após a cirurgia, que não detetou a pinça.

- Cerca de um ano após a data da cirurgia, realizou-se tomografia axial computorizada que revelou uma imagem de corpo estranho localizado na região abdominal anterior.

- A pinça causou algum desconforto e incómodo à doente e a imprescindibilidade de realização de nova intervenção cirúrgica para remoção do referido corpo estranho.

Foi pedida análise técnico-científica ao Conselho Médico-Legal, cuja apreciação permitisse um perfeito enquadramento do caso e uma melhor e mais adequada análise crítica à situação.

O parecer deste Conselho referiu que "as boas práticas de atuação em salas de operações determinam a contagem de compressas e instrumentos cirúrgicos, e sempre que não haja concordância dos números o cirurgião deverá proceder a uma exploração cirúrgica e radiológica antes de encerrar a cavidade abdominal”, sendo, no presente caso, "de óbvia conclusão que a referida contagem, se tivesse sido efectuada, não poderia estar correta”.

A apreciação final foi de que a presença de um instrumento retido após uma intervenção cirúrgica não evidencia, claramente, a violação das leges artis, sendo um caso de acidente operatório inerente a erro, próprio da condição humana, dos elementos que integram a equipa cirúrgica.

No entanto, o Ministério Público deduziu acusação contra o médico-cirurgião responsável pela cirurgia e contra duas enfermeiras presentes na mesma cirurgia, seguindo o processo para julgamento.

Posteriormente, conforme "termo de transação" de tribunal de $1^{a}$ instância, a assistente desistiu do procedimento criminal contra os três arguidos, que aceitaram tal desistência, tendo-se chegado a acordo sobre o litígio respeitante ao pedido de indemnização civil - $14.400 €$ ao médico-cirurgião demandado e $10.600 €$ às enfermeiras demandadas. 


\section{Transferência causa a morte do doente}

A fim de ser julgada em processo comum e por tribunal singular, o Ministério Público acusou uma médica especialista de Cardiologia pela prática de um crime de homicídio por negligência.

- Quando se encontrava de urgência num hospital central na cidade de Coimbra a referida médica atendeu um doente do género masculino de 72 anos de idade, transferido de um hospital distrital, com o diagnóstico de "suspeita de enfarte agudo do miocárdio".

- Após a realização de novos exames laboratoriais, anotou no diário clínico do doente "padrão enzimático compatível com enfarte em evolução", e medicou o doente. Foi, ainda, pedida observação pela Medicina Interna, que atestou "que o doente estaria a fazer um enfarte agudo do miocárdio", atendendo sobretudo aos dados analíticos e à clínica.

- No mesmo dia, a mesma médica cardiologista que tinha o doente a seu cargo, decidiu dar alta ao doente e ordenar o seu regresso ao mesmo hospital distrital - hospital este que não dispunha de cuidados intensivos gerais e muito menos especializados, nomeadamente de Cardiologia, e que se situava a cerca de $100 \mathrm{~km}$ da cidade de Coimbra - com informação médica de saída de "alterações analíticas compatíveis com enfarte e pneumonia".

- No dia seguinte, após ter dado entrada no referido hospital distrital, o estado do doente degradou-se significativamente, com as funções renal, hepática e cardio-respiratória em falência. Não tendo, este hospital, médicos da especialidade de Cardiologia, foi novamente transferido para outro hospital distrital mais próximo, onde realizou novos exames e nova avaliação. Por este hospital distrital também não apresentar cuidados intensivos com ventilação assistida, nem a possibilidade de realizar os exames necessários, o doente foi transferido para o mesmo hospital central da cidade de Coimbra.

- À entrada, no Serviço de Urgência deste hospital, continuava numa situação muito grave, com falência multiorgânica, vindo a falecer algumas horas depois.

Foi submetido a autópsia médico-legal, que permitiu concluir que a morte foi devida a enfarte agudo do miocárdio por coronariopatia estenosante, com evolução de cerca de 18-24 horas - ocorrida, por isso, no hospital distrital após a alta do hospital central da cidade de Coimbra.

Foi pedida consulta técnico-científica ao Conselho Médico-Legal, que entendeu que "a decisão de reenviar o doente para o hospital distrital de origem não foi a correta”. 
Refira-se ainda que a Inspeção-Geral das Actividades em Saúde instaurou um processo disciplinar contra a médica arguida, onde também se concluiu que "não atuou com a necessária prudência e cautela".

Os factos foram dados como provados, pelo que a médica cardiologista não atuou com a diligência necessária que o caso impunha e decidiu erradamente transferir o doente para o hospital de origem, cometendo o crime de "homicídio por negligência".

A arguida foi condenada pela prática de um crime de homicídio por negligência, na pena de 280 dias de multa, à taxa diária de $30 €$, o que perfez a quantia de $8.400 €$.

\section{DISCUSSÃO/CONCLUSÕES}

Durante séculos a actividade médica esteve centrada e encerrada em si mesma, criando uma lógica própria de solidariedade entre os seus pares. $\mathrm{O}$ médico era detentor do conhecimento, agia com intenção de curar segundo as regras da sua arte e mesmo que alguma coisa corresse mal nem ele dava explicações, nem os doentes nem os familiares as pediam.

Atualmente a relação médico-doente tornou-se mais impessoal. Embora nem sempre seja possível a cura do doente, este pode exigir ao médico que faça tudo o que estiver ao seu alcance para melhorar o seu estado de saúde.

A consciencialização pelos "consumidores” de serviços médicos dos seus direitos, consequente ao processo de democratização da nossa sociedade, originando um fenómeno de tentativa de responsabilização a todo o custo dos médicos e das entidades prestadoras dos cuidados de saúde, culminou num aumento do número de ações judiciais de responsabilidade médica, porventura até ao exagero.

De um período em que o doente e/ou os seus familiares aceitavam com resignação o insucesso - e porventura até a morte - de um tratamento efetuado pelo médico, passou-se para o outro extremo, em que se procura imputar, muitas vezes injustamente, esse insucesso a um pretenso erro médico.

O sucesso de alguns pedidos de indemnização em tribunal pode ter levado à participação de situações de assistência potencialmente desadequada, mesmo quando não existe culpa dos médicos ou quando poderia até haver outras soluções.

Não obstante a consciência de que não é fácil aceitar-se a morte dos entes queridos e que se tenta sempre encontrar alguma explicação para tal acontecimento, à boa maneira da filosofia judaico-cristã, o que é certo é que muitas vezes a morte não é determinada pela atuação de qualquer terceira pessoa. 
O doente deve saber no que consente, em que consiste o tratamento e os riscos de a ele se submeter, bem como o que comporta a negação, o que pressupõe uma informação, pelo menos, clara e suficiente. Deve ainda aceitar que a legitimação decorrente do consentimento esclarecido envolve uma aceitação dos riscos próprios (normais ou conhecidos num certo estádio da evolução da ciência) da intervenção.

No domínio do ato médico, onde é particularmente patente a existência de procedimentos de risco, é exigida a especial preparação técnica dos profissionais de saúde, cuja atuação adequada deverá ser orientada em conformidade com as regras resultantes das leges artis.

No âmbito médico nem sempre é possível distinguir entre erro e falta médica, pois o exercício desta actividade é inseparável de riscos que podem por vezes induzir o próprio médico em erro. Assim, condenar sistematicamente o erro conduz a condenar a própria Medicina, cuja evolução se verifica por uma sucessão de audácias, fracassos e renovações.

Esta responsabilidade é do juiz, que através de um juízo de prognose decide sobre a violação do dever objetivo de cuidado por parte do profissional de saúde. Como este não possui, em princípio, conhecimentos médicos, poderá solicitar consultas técnico-científicas ao Conselho Médico-Legal do Instituto Nacional de Medicina Legal e Ciências Forenses, com o objectivo de assessoria técnica à decisão judicial.

Estas perícias são abrangentes, coerentes e esclarecedoras e, uma vez que o juízo técnico e científico inerente à prova pericial se presume subtraído à livre apreciação do julgador, perante a composição deste Conselho, com os elevados conhecimentos técnicos dos membros que o compõem, impõe-se um valor probatório inabalável e dificilmente colocado em causa por outros meios de prova.

A Medicina não é uma ciência exata, e, por isso, não podem afirmar-se com certeza os resultados derivados de um tratamento ou intervenção cirúrgica na sua totalidade.

Muitas vezes surgem opiniões técnicas contraditórias que dificultam a tarefa de quem é chamado a decidir. Por outro lado, nem sempre é fácil provar que foi a falta de cuidado do médico que causou a lesão ou a morte do doente, assim como definir a violação do cuidado no apuramento do que era de esperar - saber se lhe era exigível mais ou se fez tudo o que era possível dadas as circunstâncias.

Não se trata da conduta esperada de um médico altamente qualificado e experimentado, mas sim da conduta diligente que a generalidade dos médicos, com idêntica qualificação e meios, teria tomado nas mesmas condições. 
Apontar o dedo ao médico sempre que existe um erro ou uma falha pode ser socialmente contraproducente, pois os médicos, sobretudo em algumas especialidades, poderão passar a recusar os casos mais complexos e com mais riscos.

Quando se opta por se ser médico, assume-se o compromisso de, acima de tudo, servir os doentes, facultando-lhes com a experiência e com os meios disponíveis, o melhor que a ciência médica recomenda.

Em Portugal, a discussão sobre o sistema mais conveniente de responsabilidade médica ainda mal começou. No entanto, ninguém pode estar satisfeito com o regime atual. Os médicos temem as acusações de negligência que os expõe nos meios de comunicação e os ameaçam com o pagamento de indemnizações. Os hospitais sentem-se desconfortáveis com a má publicidade que os "casos" lhes trazem e receiam os custos da Medicina defensiva que facilmente se pode esperar.

Tornar o sistema menos vulnerável, com um melhor registo dos atos clínicos, mas também promover resoluções extrajudiciais e prever indemnizações para procedimentos que correm mal sem ser por negligência de médico, poderão ser algumas das soluções para aliviar o sistema, sendo que todas as medidas que venham reduzir a conflitualidade doente-médico são bem-vindas.

Um sistema de monitorização dos erros, que recolha e centralize a informação de forma não punitiva e confidencial, tornando possível o seu estudo por peritos, poderá permitir uma aprendizagem com os erros e emitir propostas de prevenção.

Por outro lado, a aplicação da responsabilidade objetiva da entidade coletiva, ainda que apoiada em seguros profissionais, diminuindo o recurso aos tribunais e acelerando as decisões, poderá ser a forma de o doente ser compensado sem ter que demonstrar a culpa dos profissionais de saúde, privilegiando a relação médico-doente e evitando um sofrimento emocional e psicológico.

No fundo, uma ideia pela socialização do risco em lugar da culpabilização do médico.

\section{Referências:}

ANDRADE, Manuel Costa - Consentimento e acordo em Direito Penal. Coimbra Editora, 1991. ANDRADE, Manuel Costa - Comentário conimbricense do Código Penal - I. Parte Especial de Jorge Figueiredo Dias. Coimbra Editora, 1999.

BRITO, Teresa Quintela de - Responsabilidade penal dos médicos: análise dos principais tipos incriminadores. Revista Portuguesa de Ciência Criminal, Ano 12, no 3, Julho-Setembro. Coimbra Editora, 2002. 
BRUNO, Paula - Registo de incidentes e eventos adversos: implicações jurídicas da implementação em Portugal - erro em Medicina. Centro de Direito Biomédico - Faculdade de Direito da Universidade de Coimbra. Wolters Kluwer Portugal - Coimbra Editora, 2010. ISBN: 978-972-32-1181-7.

CORDEIRO, Pedro Jorge da Silva - Responsabilidade médica disciplinar no Serviço Nacional de Saúde. In Direito da Medicina - I; Centro de Direito Biomédico - Faculdade de Direito da Universidade de Coimbra. Coimbra Editora, 2002. ISBN: 972-32-1122-X. Páginas 165-158.

CORTEZ, Margarida - Responsabilidade civil das instituições públicas de saúde. In Responsabilidade civil dos médicos; Centro de Direito Biomédico - Faculdade de Direito da Universidade de Coimbra. Coimbra Editora, 2005. ISBN: 972-32-1369-9. Páginas 257-273.

DIAS, João Álvaro - Responsabilidade, informação, consentimento e confidencialidade. In Revista Portuguesa do Dano Corporal No 4 - Associação Portuguesa de Avaliação do Dano Corporal (APADAC). Maio de 1994. Páginas 9 a 32.

DIAS, João Álvaro - Culpa médica: algumas ideias-força. In Revista Portuguesa do Dano Corporal No 5 - Associação Portuguesa de Avaliação do Dano Corporal (APADAC). Novembro de 1995. Páginas 15 a 46.

DIAS, João Álvaro - Responsabilidade profissional do perito médico. In Revista Portuguesa do Dano Corporal No 8 - Associação Portuguesa de Avaliação do Dano Corporal (APADAC). Novembro de 1998. Páginas 35 a 51.

DIAS, João Álvaro - O problema da avaliação dos danos corporais resultantes de intervenções e tratamentos médico-cirúrgicos. In Responsabilidade civil dos médicos; Centro de Direito Biomédico - Faculdade de Direito da Universidade de Coimbra. Coimbra Editora, 2005. ISBN: 972-32-1369-9. Páginas 387-433.

DIAS, Jorge Figueiredo e MONTEIRO, Jorge Sinde - Responsabilidade médica em Portugal. Lisboa, 1984.

FARIA, Paula Ribeiro - in: Comentário conimbricense do Código Penal, Parte Especial, dirigido por Jorge Figueiredo Dias, t.I. Coimbra Editora, 1999.

FIDALGO, Sónia - Responsabilidade penal por negligência no exercício da Medicina em equipa. Centro de Direito Biomédico - Faculdade de Direito da Universidade de Coimbra. Coimbra Editora, 2008. ISBN: 978-972-32-1634-9.

GONÇALVES, Carla - A responsabilidade médica objetiva. In Responsabilidade civil dos médicos; Centro de Direito Biomédico - Faculdade de Direito da Universidade de Coimbra. Coimbra Editora, 2005. ISBN: 972-32-1369-9. Páginas 333-357.

LOPES, Diamantino Marques - Responsabilidade civil médica - casos práticos. In Responsabilidade civil dos médicos; Centro de Direito Biomédico - Faculdade de Direito da Universidade de Coimbra. Coimbra Editora, 2005. ISBN: 972-32-1369-9. Páginas 274-287.

MONIZ, Ana Raquel Gonçalves - Responsabilidade civil extracontratual por danos resultantes da prestação de cuidados de saúde em estabelecimentos públicos: o 
acesso à justiça administrativa. Centro de Direito Biomédico - Faculdade de Direito da Universidade de Coimbra. Coimbra Editora, 2003. ISBN: 972-32-1183-1.

MONIZ, Ana Raquel Gonçalves - Aspectos processuais da responsabilidade médica: as questões colocadas pelos hospitais S.A. quanto ao âmbito da justiça administrativa. In Responsabilidade civil dos médicos; Centro de Direito Biomédico - Faculdade de Direito da Universidade de Coimbra. Coimbra Editora, 2005. ISBN: 972-32-1369-9. Páginas 317-331.

NUNES, José Martins - Da responsabilidade dos médicos anestesiologistas: dos diversos tipos de responsabilidade, formas de apuramento e instâncias decisórias: consentimento informado. Coimbra, 2009.

OLIVEIRA, Guilherme de - Estrutura jurídica do acto médico, consentimento informado e responsabilidade médica. In Temas de Direito da Medicina - Centro de Direito Biomédico. Coimbra Editora, 2005.

OLIVEIRA, Guilherme de - O fim da "arte silenciosa". In Temas de Direito da Medicina - Centro de Direito Biomédico. Coimbra Editora, 1999.

OLIVEIRA, Guilherme de - Recensão de José Fragata e Luís Martins - O erro em Medicina. Perspectiva do indivíduo, da organização e da sociedade. Coimbra, Almedina, 2005.

OLIVEIRA, Nuno Manuel Pinto - Responsabilidade civil em instituições privadas de saúde: problemas de ilicitude e de culpa. In Responsabilidade civil dos médicos; Centro de Direito Biomédico - Faculdade de Direito da Universidade de Coimbra. Coimbra Editora, 2005. ISBN: 972-32-1369-9. Páginas 127-255.

PEREIRA, André Gonçalo Dias - O dever do esclarecimento e a responsabilidade médica. In Responsabilidade civil dos médicos; Centro de Direito Biomédico - Faculdade de Direito da Universidade de Coimbra. Coimbra Editora, 2005. ISBN: 972-32-1369-9. Páginas 435-497.

PEREIRA, André Gonçalo Dias - Breves notas sobre a responsabilidade médica em Portugal. In Revista Portuguesa do Dano Corporal No 17 - Associação Portuguesa de Avaliação do Dano Corporal (APADAC). Novembro de 2007. ISSN: 1645-0760.

PINA, J.A. Esperança - A responsabilidade dos médicos. Lidel, 2003 (3 $3^{\text {a }}$ Edição). ISBN: 978-972-757-195-6.

REIS, Rafael Vale - Responsabilidade civil dos médicos nos estabelecimentos públicos de saúde - origens históricas. In Responsabilidade civil dos médicos; Centro de Direito Biomédico - Faculdade de Direito da Universidade de Coimbra. Coimbra Editora, 2005. ISBN: 972-32-1369-9. Páginas 289-316.

RODRIGUES, Álvaro da Cunha Gomes - Consentimento informado - Pedra angular da responsabilidade criminal do médico. In Direito da Medicina - I; Centro de Direito Biomédico - Faculdade de Direito da Universidade de Coimbra. Coimbra Editora, 2002. ISBN: 972-32-1122-X. Páginas 5-51.

SILVEIRA, Diana Filipa Montenegro - Responsabilidade civil por reacções adversas medicamentosas. In Responsabilidade civil dos médicos; Centro de Direito Biomédico 
- Faculdade de Direito da Universidade de Coimbra. Coimbra Editora, 2005. ISBN: 972-32-1369-9. Páginas 333-357.

VARELA, João de Matos Antunes - Das obrigações em geral. Vol. I - $10^{\text {a }}$ edição revista e actualizada. Coimbra, Almedina, 2000.

VIEIRA, Duarte Nuno e SÁ, Fernando Oliveira - Conselhos Médico-Legais - In memoriam.

In Confluências - temas médico-legais; Homenagem ao Prof. Doutor L. A. Duarte-

-Santos. Instituto de Medicina Legal de Coimbra, Dezembro de 1989. Páginas 487-497.

VIEIRA, Duarte Nuno - O atual sistema médico-legal e forense português. Janeiro de 2012. 